\title{
Projeksiyon Kaynağında DP600 Çeliklerde Elektrot Baskı Kuvvetinin Punta Kalitesine Etkisi
}

\author{
${ }^{*}$ Mustafa YAZAR, ${ }^{1}$ Milat KUL, ${ }^{1}$ Ayşegül YILDIZ, ${ }^{1}$ Eyüp Mutlu, ${ }^{1}$ Samet BALKAN, ${ }^{1}$ Erhan KUL, ${ }^{1}$ Melih \\ ÇAYLAK, ${ }^{1}$ Ali Kemal ALP, ${ }^{2}$ Şükrü TALAŞ \\ ${ }^{* 1}$ AR\&GE Merkezi, Şahinkul Makina ve Yedek Parça San. Tic. A.Ş, Bursa, Türkiye \\ ${ }^{2}$ Afyon Kocatepe Üniversitesi, Teknoloji Fakültesi, Metalurji ve Malzeme Mühendisliği Bölümü, \\ Afyonkarahisar, Türkiye
}

\section{Özet}

$\mathrm{Bu}$ çalışmada, MFDC trafolu $100 \mathrm{kVA}$ projeksiyon kaynak makinasında baskı kuvvetin punta kalitesine olan etkisi incelenmiştir. Hazırlanan numuneler tam tahribatlı test cihazı ile kopma yükü kuvveti testine tabi tutulmuştur. $\mathrm{Bu}$ çalışmada, başta otomotiv ana sanayinin şartnamelerle belirlemiş olduğu punta kalitesini yakalayarak ürün güvenliğini sağlamaktır. Çalışmamızda 1,5 mm DP600 kaplamasız çelik saç ve kaynak civatası olarak 8,8 kalite M8x1,25x25 üç memeli kaplamasız kaynak cıvatası kullanılmıştır. Hazırlanan DP600 çelik saç numuneleri ve kaynak cıvataları ile puntalama operasyonunda kaynak zamanı $30 \mathrm{~ms}$, akım değeri $18 \mathrm{kA}$ de sabit tutulmuştur. Düşük, orta ve yüksek kuvvet değerleri verilerek optimum parametrelerinin farklı elektrot baskı kuvvet değerlerinin punta kalitesine etkisi incelenmiştir. Yapılan testlerde elektrod bask1 kuvveti 230 - 730 daN arasında bulunmuştur. Sonuçlar kopma kuvvetlerinin 430 ile 530 daN arasında yüksek mukavemet değeri yakalandığı göstermiştir.

Anahtar Kelimeler: Projeksiyon kaynağı; Elektrod baskı kuvveti; Kaynak civatası; DP600 çelik saç

\section{Effect of ElectrodePressure Force on Tailstock Quality in DP600 Steels at Projection Source}

\begin{abstract}
In this study, the effect of compression force on spot quality in a $100 \mathrm{kVA}$ projection welding machine with MFDC transformer was investigated. The prepared samples were subjected to the rupture load force test with a fully destructive test device. In this study, the aim is to achieve a product safety by obtaining the spot weld quality that the automotive main industry has set by the specifications. In our study, $1.5 \mathrm{~mm}$ DP600 uncoated steel plate and uncoated 8.8 quality M8x1,25x25 welding bolts with three projections were used. During the projection welding operation experiment with DP600 steel sheet samples and welding bolts, the welding time was kept constant at $30 \mathrm{~ms}$ and the current value at $18 \mathrm{kA}$. By giving low, medium and high force values, optimum parameter were determined and the effect of different electrode pressure values on spot weld quality were examined. The electrode compression values were found to be between 230- $730 \mathrm{daN}$ in the tests carried out. The results showed that high rupture forces were achieved between 430 to 530 daN.
\end{abstract}

Keywords: Projection weld; Electro compression force; Weld bolt; DP600 steel sheet

\section{Giriş}

Günümüzde birçok endüstri alanında yaygın olarak kullanılan kaynak yöntemlerinden biri olan projeksiyon kaynağı, iş parçalarından geçen elektrik akımına karşı temas noktalarındaki dirençten sağlanan 1S1 ve aynı zamanda parçalara uygulanan basıncın tatbikiyle yapılan bir 
kaynak yöntemidir. Isı, kaynak edilecek cıvata kaynak memelerinde akım yoğunlaşması ile meydana gelir ve basınç kaynak makinasındaki elektrotlar vasıtasıyla civata puntalama operasyonu gerçekleşir. Otomotiv ana sanayinde ve bunlara bağlı alt kuruluşlarında kullanılan projeksiyon kaynak makinaları AC ve MFDC trafolu olanları mevcuttur [1]. Bu ikisi arasındaki fark ise AC trafolu projeksiyon kaynak makinalarında elektrik frekans1 $50 \mathrm{~Hz}$, MFDC trafolu kaynak robotlarının elektrik frekans1 $1000 \mathrm{~Hz}$ olarak kullanılmaktadır.

Literatürde yapılan çalışmalar çoğunlukla projeksiyon kaynağının farklı sac kalınlıkları ve kaynak parametrelerinin (kaynak akımı, impuls sayısı, kaynak süresi ve elektrot basıncı) yeni nesil çeliklerin mekanik özellikleri üzerindeki etkisi konusunda yoğunluk kazanmıştır [2].

Günümüzde artan çevre bilinci ile hava kirliliğinde etkin bir role sahip taşıt kaynaklı kirleticilerin azaltılması konusunda birçok çalışma yapılmaktadır. Azalan petrol rezervleri ile birlikte yakıt fiyatlarının artması da otomotiv sektöründe hafif taşıtlara ilgiyi ve rekabeti arttırmıştır. Son zamanlarda taşıtların hafifletilmesinde alüminyum, magnezyum, titanyum alaşımları ve yüksek mukavemetli çelikler gibi metal alaşımlar bu amaçla kullanılan malzemelerdendir [3].

Çelik sektöründeki hızlı ilerleyiş ile birlikte ileri yüksek mukavemetli çelikler (AHSS) olarak yeni nesil çelik kaliteleri geliştirilmektedir [4]. İleri yüksek mukavemetli çelikler ürün grubunda bulunan çift fazlı (DP) çelikler yüksek dayanım, mükemmel süneklik, iyi kaynak edilebilirlik ve çarpışma testlerinde yüksek enerji absorbsiyon kabiliyeti özelliklerine sahiptir [5]. Şekil 1'de DP600 çeliklerin otomotivde kullanım yerleri gösterilmiştir.

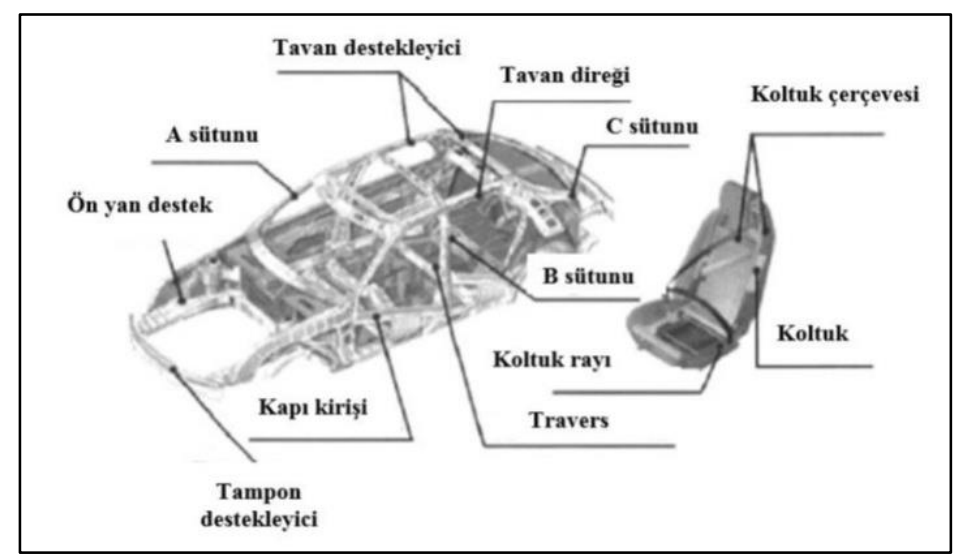

Şekil 1. DP600 çeliklerin otomotivde kullanım yerleri.

$\mathrm{Bu}$ çalışmada bağlantı elemanı olarak 3 memeli kaynak cıvatası projeksiyon kaynağı ile puntalama operasyonu yapılmıştır. Akım değeri ve kaynak zamanı sabit tutularak elektrot baskı kuvvetinin punta kalitesine etkisini gözlemleyerek iyileştirme önerilmiştir.

\section{Materyal ve Metod}

\subsection{Malzeme}

\subsubsection{DP600 çelik saç malzeme ve kaynak civatası}

Deneylerde kullanılan 1,5 mm kalınlığındaki kaplamasız ticari DP600 çeliğinin kimyasal bileşimi Tablo 1 ve mekanik özellikleri Tablo 2'de gösterilmiştir.

Tablo 1. DP600 çeliğine ait kimyasal analiz. (\% ağırlık). 


\begin{tabular}{|l|l|l|l|l|l|l|l|l|l|}
\hline Element & $\mathbf{C}$ & $\mathbf{S i}$ & $\mathbf{M n}$ & $\mathbf{C r}$ & $\mathbf{N b}$ & $\mathbf{N i}$ & $\mathbf{T i}$ & $\mathbf{M o}$ & $\mathbf{A l}$ \\
\hline \% Oran1 & 0,11 & 0,18 & 1,6 & 0,34 & 0,003 & 0,027 & 0,002 & 0,098 & 0,05 \\
\hline
\end{tabular}

Tablo 2. DP600 çeliğine ait mekanik özellikler.

\begin{tabular}{cccc}
\hline Malzeme & $\begin{array}{c}\text { Akma } \\
\text { Dayanımı } \\
\text { (MPa) }\end{array}$ & $\begin{array}{c}\text { Çekme } \\
\text { Dayanımı } \\
\text { (MPa) }\end{array}$ & $\begin{array}{c}\text { Uzama } \\
(\%)\end{array}$ \\
\hline $\begin{array}{c}\text { 1,5mm } \\
\text { Kaplamasız }\end{array}$ & $330-430$ & 590 & 20 \\
$\begin{array}{c}\text { DP600 Çelik } \\
\text { Saç }\end{array}$ & & & \\
& & \\
\hline
\end{tabular}

DP600 çelik saçtan hazırlanan numunelere, M8 kaynak cıvatası puntalama delikleri onda bir boşluk verilerek çelik saç üzerine boşaltmalar yapılmıştır. Hazırlanan test numuneleri Şekil 3' te verilmiştir.

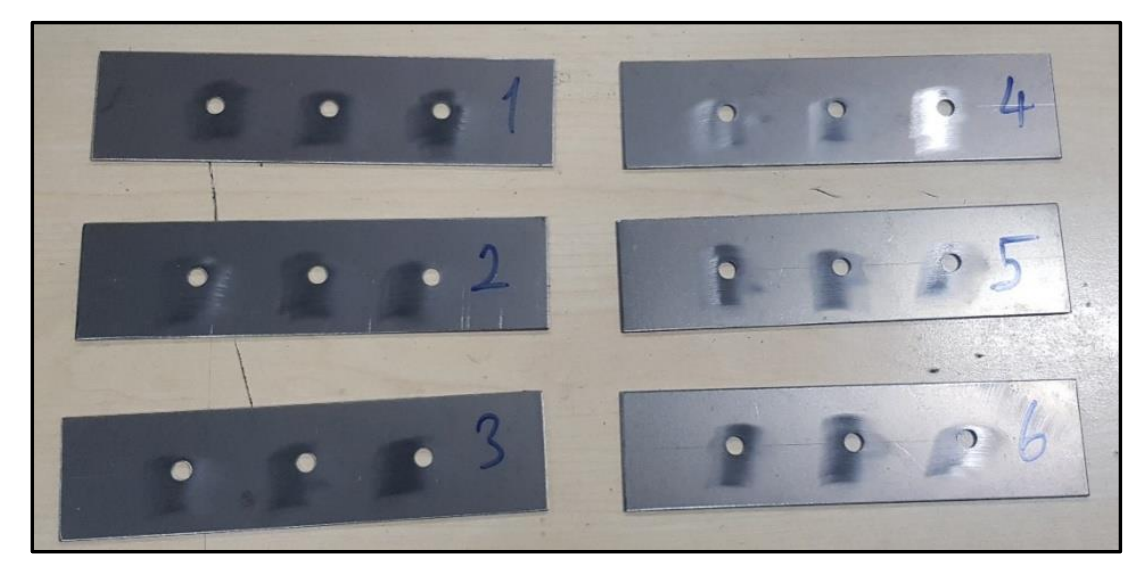

Şekil 3. D600 çelik saç test numuneleri görseli.

Elektrot bask1 kuvveti 230, 330, 430, 530, 630, 730daN olarak; 6 adet 200x20x1,5 mm ölçüsünde DP600 çelik saçlardan hazırlanmış olan numunelere 3'er adet kaynak civatası puntalama operasyonu gerçekleştirilip, tam tahribatlı test sonucunda kopma yükü kuvvetlerinin sonuçları karşılaştırılmıştır.

Deneylerde kullanılan 3 memeli 8,8 kalite M8x1,25x25 kaynak cıvatası görseli Şekil 4'de verilmiş olup ölçeklendirmesi Tablo 3' te gösterilmiştir. Mekanik özellikleri ise Tablo 4' de verilmiştir. 


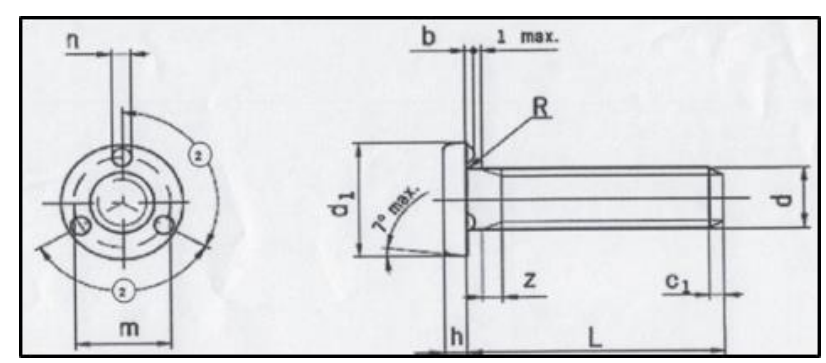

Şekil 4. Kaynak cıvatası.

Tablo 3. Kaplamasız bağlantı elemanı ölçekleri (mm).

\begin{tabular}{|l|l|l|l|l|l|l|l|l|l|}
\hline Birim & $\mathbf{b}$ & $\mathbf{d}$ & $\mathbf{d} \mathbf{1}$ & $\mathbf{h}$ & $\mathbf{m}$ & $\mathbf{n}$ & $\mathbf{L}$ & $\mathbf{R}$ & $\mathbf{z}$ \\
\hline $\mathrm{mm}$ & 1,3 & 8 & 17 & 3,5 & 13 & 3 & 25 & 0,3 & 3,1 \\
\hline
\end{tabular}

Tablo 4. Kaynak cıvatası mekanik özellikleri.

\begin{tabular}{cccc}
\hline Malzeme & $\begin{array}{c}\text { Akma } \\
\text { Dayanımı } \\
(\mathbf{M P a})\end{array}$ & $\begin{array}{c}\text { Çekme Dayanımı } \\
(\mathbf{M P a})\end{array}$ & Uzama (\%) \\
\hline $\begin{array}{c}\text { 8.8 Kalite M8x1,25x25 } \\
\text { Kaynak civatası }\end{array}$ & 640 & 800 & 12 \\
\hline
\end{tabular}

\subsection{Metod projeksiyon kaynă̆ı ile punta operasyonu}

Projeksiyon kaynağında cıvata puntalama öncesi MFDC trafolu 100 kVA sabit punta makinasında yapılması gerekenler üç adımdan oluşmaktadır. Bunlar, a) su ve hava debisinin kontrolü, b) elektrod kuvvet ve akım değerleri kontrolü ve c) eksenellik kontrolü. MFDC trafo 100 kVA projeksiyon kaynak makinası ile kaynak zamanı akım değeri ve puls değerleri sabit tutulmuştur. Civata puntalama prosesi Şekil 5'te gösterilmiştir.

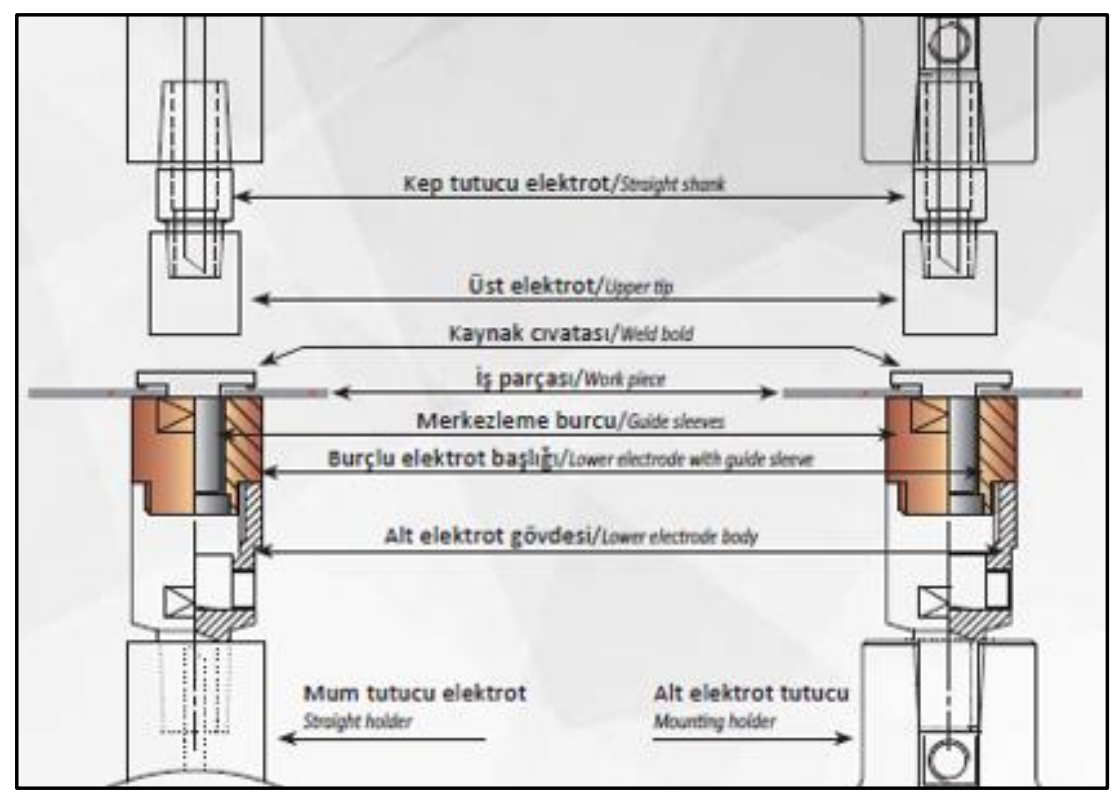

Şekil 5. Kaynak cıvatası puntalama prosesi. 
Kaynak cıvatasında 3 memenin şartnamede belirtilen en, boy ve yükseklikte olması gerekmektedir [6]. Kaynak cıvatasının yüzeyinde kaynak memesinin oluşmamış olması veya 3 adet kaynak memesi eşit yükselikte değiller ise kaynak akımı tercihli atlama yapacağ 1 için yani tüm uçlarda eşit akım yoğunluğuna sahip olmayacağı istenen kopma yükü değeri sağlanamamakta ve dinamik yüklerde istenen performansı vermemektedir. Projeksiyon kaynağında civata puntalama prosesinde kullanılan değerler Tablo 5'de gösterilmiştir.

Tablo 5.Civata puntalama parametre değerleri.

\begin{tabular}{|l|c|c|c|}
\hline \multicolumn{1}{|c|}{ Numuneler } & Kaynak Zamanı (ms) & Akım Değeri (kA) & Elektrot Baskı Kuvveti(daN) \\
\hline 1. Test parçası & 30 & 18 & 230 \\
\hline 2. Test parçası & 30 & 18 & 330 \\
\hline 3. Test parçası & 30 & 18 & 430 \\
\hline 4. Test parçası & 30 & 18 & 530 \\
\hline 5. Test parçası & 30 & 18 & 630 \\
\hline 6. Test parçası & 30 & 18 & 730 \\
\hline
\end{tabular}

\subsection{Kopma kuvveti testi}

Kopma yükü testi tam tahribatlı olarak gerçekleştirilmiştir. Tablo 6'da kopma kuvveti test cihazının teknik donanımı, Şekil 6'te ise kopma kuvveti test prosesi gösterilmiştir. 6 adet test parçası kopma kuvveti testine tabi tutularak ölçülen değerler üstüne yazılmıştır. Kullanılan test cihazı firma bünyesinde hazırlanmış olup dijital sensör kısmını ihtiva eden cihaz kalibre edilmektedir.

Tablo 6. Kaynak cıvatası mekanik özellikleri.

\begin{tabular}{cccc}
\hline \multicolumn{1}{c}{ Teçhizat } & Güç & $\begin{array}{c}\text { Yük } \\
\text { Kapasitesi }\end{array}$ & $\begin{array}{c}\text { Gösterge } \\
\text { Paneli }\end{array}$ \\
\hline $\begin{array}{l}\text { Kopma Kuvveti } \\
\text { Test Cihazı }\end{array}$ & $1,5 \mathrm{~kW}$ & $20 \mathrm{kN}$ & Dijital \\
\hline
\end{tabular}

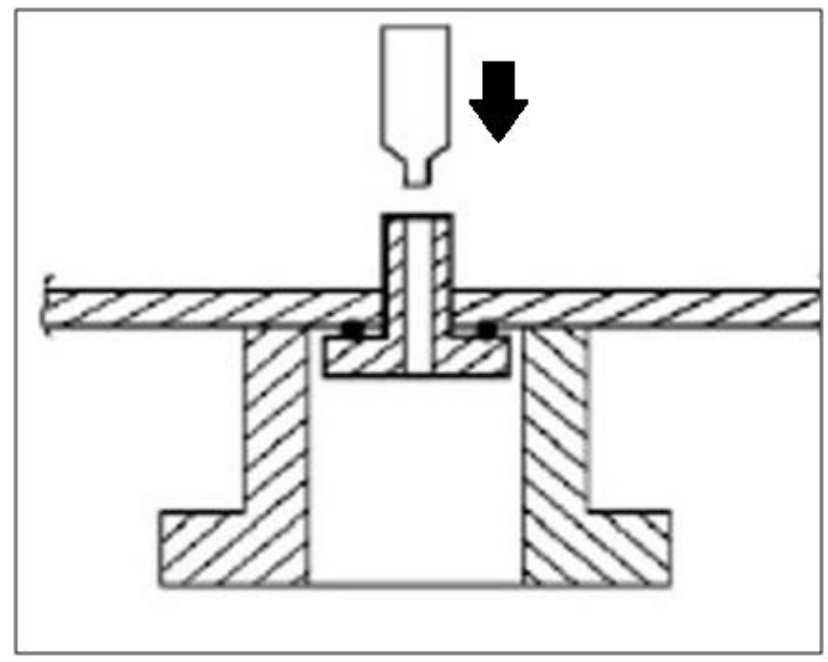

Şekil 6. Kaynak cıvatası kopma kuvveti test prosesi. 


\section{Bulgular ve Tartışma}

\section{1. Mekanik özellikler}

Elektrot bask1 kuvveti 230, 330, 430, 530, 630, 730daN olarak seçilmiş olup, 200x20x1,5 mm ölçüsünde DP600 çelik saçlardan hazırlanmış olan numunelere 3'er adet kaynak civatası puntalaması yapılmıştır. Saplama puntalamasının ardından tam tahribatlı test sonucunda kopma yükü kuvvetlerinin sonuçları karşılaştırılmıştır. Tam tahribatlı numune test sonuçları Tablo 7'de gösterilmiştir.

Tablo 7. Kaynak cıvatası kopma kuvveti test parçaları tablosu.

\begin{tabular}{|l|c|c|c|c|c|c|r|}
\hline Numuneler & $\begin{array}{c}\text { Kaynak } \\
\text { Zamanı } \\
(\mathbf{m s})\end{array}$ & $\begin{array}{c}\text { Akım } \\
\text { Değeri } \\
\mathbf{( k A )}\end{array}$ & $\begin{array}{c}\text { Elektrot } \\
\text { Baskı } \\
\text { Kuvveti } \\
(\mathbf{d a N})\end{array}$ & $\begin{array}{c}\text { Kopma } \\
\text { Kuvveti } \\
\text { Değeri } \\
\text { Ortalama } \\
(\mathbf{d a N})\end{array}$ & $\begin{array}{c}\text { Normalize } \\
\text { Edilmiş } \\
\text { Kopma } \\
\text { Kuvveti } \\
\text { Değeri } \\
\text { Ortalama } \\
\text { (daN) }\end{array}$ & $\begin{array}{c}\text { Standard } \\
\text { Sapma }\end{array}$ & $\begin{array}{c}\text { Normalize } \\
\text { edilmiş } \\
\text { standard } \\
\text { sapma }\end{array}$ \\
\hline 1. Test parçası & 30 & 18 & 230 & 307 & 307 & 36.17 & 36.16 \\
\hline 2. Test parçası & 30 & 18 & 330 & 294 & 294 & 93.55 & 93.55 \\
\hline 3. Test parçası & 30 & 18 & 430 & 665 & 665.6 & 91.15 & 91.15 \\
\hline 4. Test parçası & 30 & 18 & 530 & 413 & 413.6 & 62.96 & 62.96 \\
\hline 5. Test parçası & 30 & 18 & 630 & 179 & 240 & 116.89 & 70.71 \\
\hline 6. Test parçası & 30 & 18 & 730 & 252 & 344 & 161.22 & 39.59 \\
\hline
\end{tabular}

Tablo 7 de görüldüğü gibi, test sonuçlarının değişim aralığ oldukca değişken olup, 5. ve 6 . test numunelerindeki çok düşük test sonuçlarının standard sapma değerlerinin yüksek çıkmasına sebep olmuştur. Bu değerlerin içerisinde standard sapması en düşük olan testlerin en düşük değerlerinin çıkarılması ile elde edilen normalize edilmiş değerlerinin oldukca dengeli bir sonuç verdiği görülmektedir.

Elektrod baskı kuvveti ile ilişkilendirildiğinde ise, ortalama değerlerinin artmadığını gözlemlemekteyiz. Normalize edilmemiş yani en düşük değerlerinin çıkarılmadığı durumdaki ortalama değerlerin standard sapma ile olan ilişkisi -0.24 olup negatif bir korelasyon vardır. Normalizasyon işleminde, en yüksek en düşük değerlerin etkisini sınırlandırmak için en düşük değerlerin birbirlerine yakınlığına, varsa en yüksek değerin ortalama değerle olan etkisine bakılır. Bu durumda, aşırı en yüksek değer çıkarılıp veya hatalı kabul edilip ortalama değerleri tekrar hesaplanır ve bu şekilde standard sapmadaki değişimlerin aşırı yüksek veya hatalı değerlerden etkilenmeden hesaplanmasına imkan tanınmaktadır. Bu korelasyon değerinin normalize edilmiş ortalama ve bunların standard sapma değerleri arasındaki korelasyon değeri ise 0.39 olup hem değer olarak ve hem de işaret olarak oldukca iyi bir korelasyon değeri vermektedir. Ancak, testlerin daha detaylı bir sonuç verebilmesi için deney sayısının daha fazla olması gerekmektedir.

Hazırlanan 6 adet test parçası üzerinde cıvata puntalama operasyonu gerçekleştirilerek tam tahribatlı kopartma testi grafik olarak gösterimi Şekil 7'de gösterilen düzenekle gerçekleştirilmiştir. Her test parçası için kaynak zamanı $30 \mathrm{~ms}$, akım değeri $18 \mathrm{kA}$ olarak sabit tutulmuştur. Kaynak özel bir işlem olduğu için ve test parçalarınında kendi içinde belli oranda dalgalanmalar ihtiva edeceğinden dolayı ortalama değerler kullanılmıştır. 


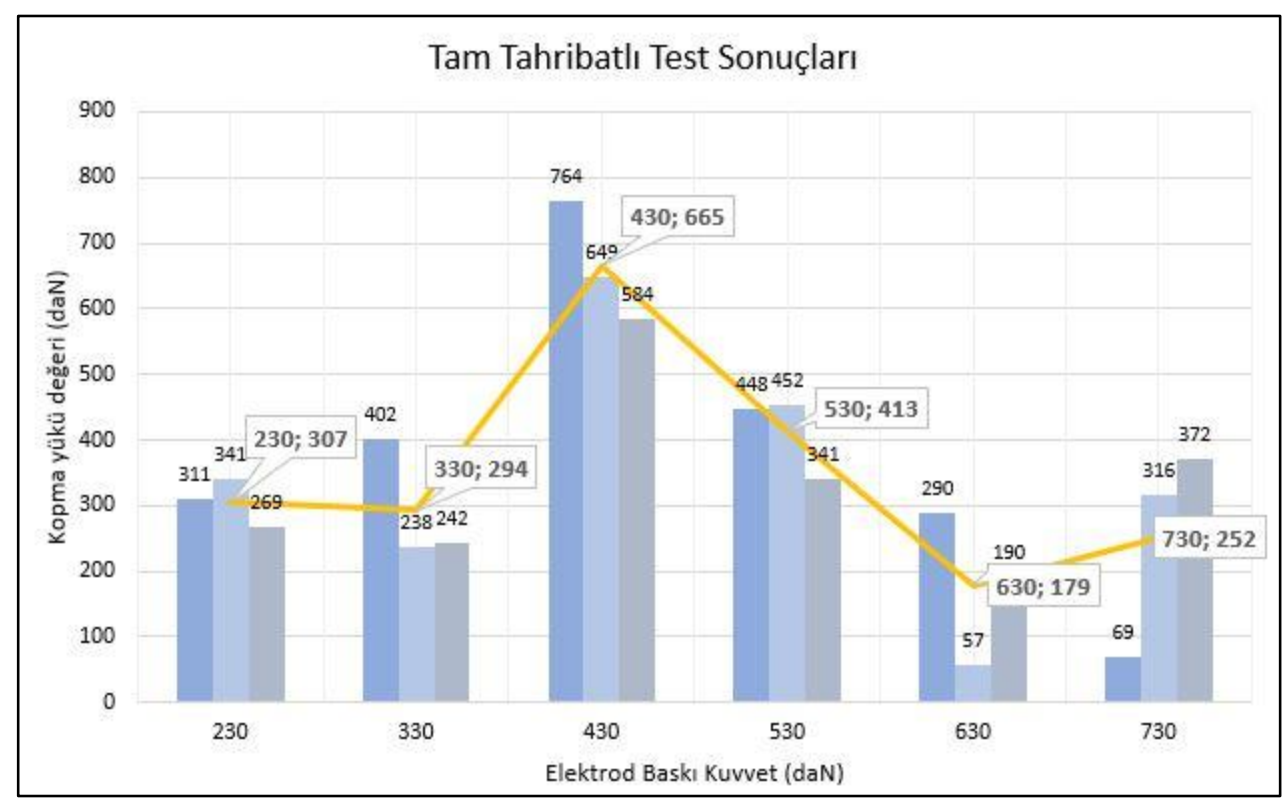

Şekil 7. Kaynak cıvatası kopma kuvveti test sonuçları.

\subsection{Deney görselleri}

Deney görselleri Şekil 8'de verilmiştir. Deney görsellerinden bütün parçaların civatalardan bağımsız bir şekilde hasar aldığı görülmektedir. Hasar mekanizmalarının bu durumda iki türlü olduğu görülmekte olup, bunların ana malzeme yani DP600 sac'ın parçalanması ile sonuçlanan koleteral hasar veya civatanın hasar görmesi ile sonuçlanan lokal hasar olduğu görülmektedir. Lokal hasarın 4, 5 ve 6 numunelerde daha çok görüldüğü tahmin edilebilir. Bu durumda ana malzemede hasar oldukca sınırlı olup sadece civatada hasar oluşmakta veya civatanın kaynak bölgesinde hasara yol açmadan düşük kuvvetle direnç göstererek koptuğu görülmektedir. Buna karşın, 2 ve 3 numaralı numunelerde, çok ciddi koleteral hasarın etkisi ile ana malzemenin parçalandığ 1 görülmektedir. Esas olarak istenen hasar türü bu olup, ana malzemenin hasar sırasında test yükünü taşıması beklenmektedir.

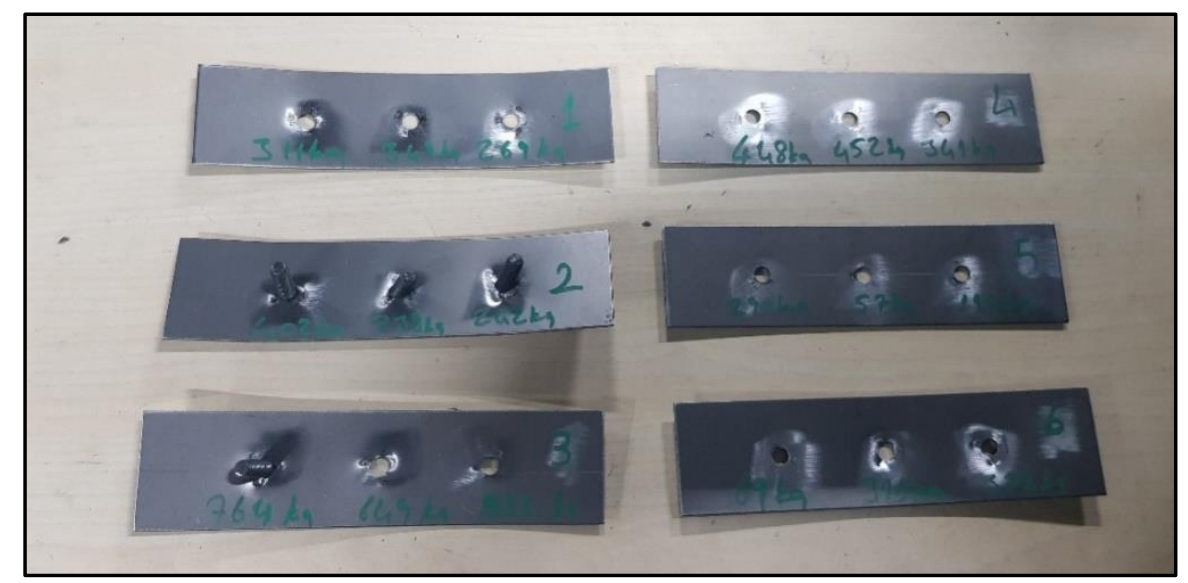

Şekil 8. Kaynak cıvatası kopma kuvveti test parçaları görseli.

Civatanın koparak yerinden çıkarıldı̆̆ı numunelerde özellikle 2. numunede hasarın çok ciddi olduğu görülmektde, aynı etkinin 3 numaralı kaynakta da görüldüğü ortaya çıkmaktadır. 
Kaynak akımının ve kaynak süresinin etkisinin olmadığı numunelerde tek etkenin bask1 kuvveti olduğu görülmektedir. Bu kuvvetin, 3 ve 4 numaralı test numunelerde sayısal olarak gerçekleştiği görülmektedir. 2 numaralı numunede yırtılmanın etkisi ile hasarın oluştuğu bu tür ince saclarda eğer homojen bir yırtılma modu yok ise, yani çatlak oluşumu ve ilerlemesi civatanın yüzey alanı ile orantılı değilse, hasar için gerekli kuvetin düşük olacağı görülmektedir. Bu nedenle, 3 ve 4 numaralı numunelerde daha az yırtılma varken 2 numaralı numunede ise tek yönlü yırtılma mevcuttur.

\subsection{Deney doğrulaması}

Deneyin doğrulamasında tam tahribatlı test sonucu kuvvetinin pik yaptığı Şekil 8' de görülen 430 daN kuvvet değeri örneklem olarak alınarak kaynak zamanı $30 \mathrm{~ms}$, akım değeri $18 \mathrm{kA}$ sabit tutularak puntalama ve tam tahribatlı test deneyi gerçekleştirilerek Tablo 8 de verilerle makine yeterliliği yapılmıştır.

Tablo 8. Kaynak cıvatası makine yeterlilik kopma kuvveti test parçaları tablosu.

\begin{tabular}{|c|c|c|c|c|c|}
\hline $\begin{array}{c}\text { Kuvvet } \\
(\text { daN) }\end{array}$ & Numuler & test 1 & test 2 & test 3 & $\begin{array}{c}\text { Ortalama } \\
\text { Kuvvet }\end{array}$ \\
\hline 430 & 1.parça & 748 & 784 & 526 & 686 \\
\hline 430 & 2.parça & 648 & 761 & 604 & 671 \\
\hline 430 & 3.parça & 782 & 861 & 734 & 792 \\
\hline 430 & 4.parça & 871 & 614 & 836 & 774 \\
\hline 430 & 5.parça & 740 & 762 & 619 & 707 \\
\hline 430 & 6.parça & 779 & 618 & 526 & 641 \\
\hline 430 & 7.parça & 798 & 586 & 517 & 634 \\
\hline 430 & 8.parça & 781 & 619 & 542 & 647 \\
\hline 430 & 9.parça & 724 & 486 & 757 & 656 \\
\hline 430 & 10.parça & 524 & 672 & 635 & 610 \\
\hline 430 & 11.parça & 458 & 523 & 609 & 530 \\
\hline 430 & 12.parça & 716 & 698 & 702 & 705 \\
\hline 430 & 13.parça & 751 & 636 & 583 & 657 \\
\hline 430 & 14.parça & 794 & 615 & 539 & 649 \\
\hline 430 & 15.parça & 862 & 703 & 718 & 761 \\
\hline
\end{tabular}

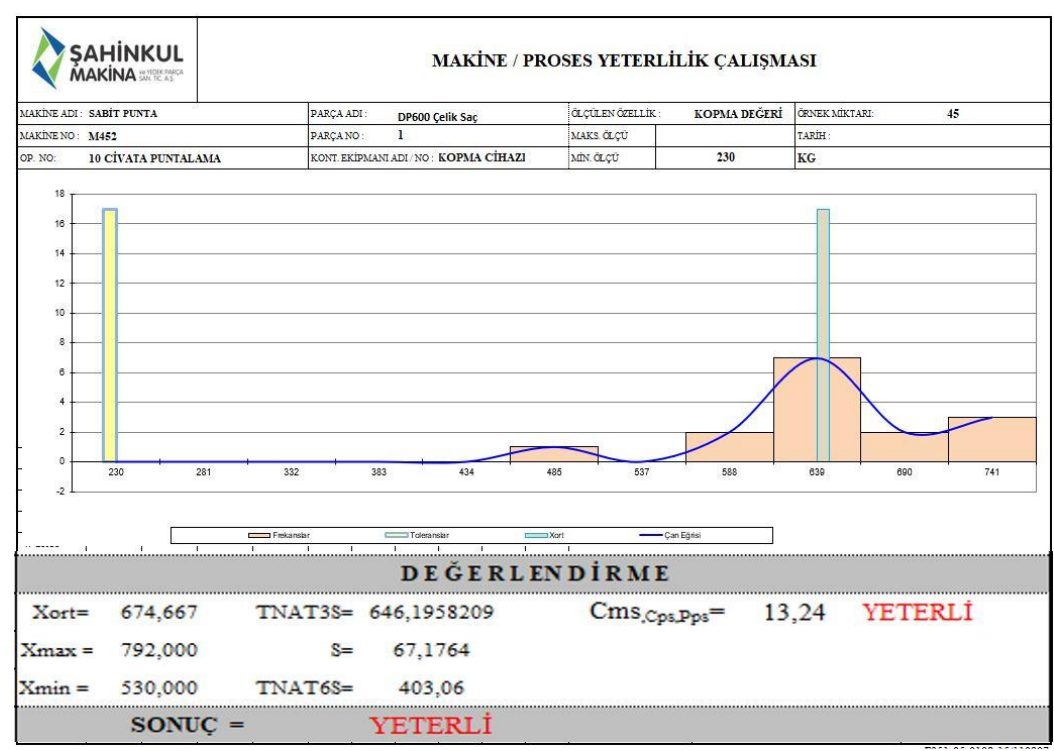

Şekil 9. Makine yeterlilik test değerleri. 


\section{Sonuçlar}

Bu çalışmadan aşağıdaki sonuçlar çıkarılabilir;

Kopma yükü kuvveti elektrod baskı kuvveti ile değişmektedir

Elektrod baskı kuvveti 4300 daN sonraki artırımlarda kopma yükü kuvveti değeri düşmüştür.

Artan elektrod baskı kuvveti ile kopma yükü kuvveti parabolik bir eğri oluşturmuşstur.

DP600 çelik saçlarda cıvata puntalama kuvvet değeri 430 ile 530daN arasında optimum değeri yakalamıştır.

230- 330 daN arası düşük elektrod baskı kuvvetinde dolayı kaynak akımının karşılaştığı direnç artığı için istenen kopma yükü değeri sağlanamamıştır.

630 ile 730 daN arasında elektrod baskı kuvvetin artması ile kaynak akımının karşılaştı̆̆ direnç düştüğü için atlama yaparak kaynak havuzu oluşamadığ için kopma yükü kuvveti düşmüştür.

\section{Teșekkür}

Bu çalışma, Bursa Şahinkul Makina ve Yedek Parça Sanayi ve Tic. A.Ş. bünyesindeki ARGE merkezi tarafından AR-GE_2020/2000550000 proje numarası ile desteklenmiştir. Teknik destek için Faruk Küçük ve Ergin Verim'e teşekkür ederiz.

\section{Kaynaklar}

[1] Buchanan, G., 2003. ResistanceWelding Manual”, RWMA, Fourth Edition, Bridgeport, NJ. U.S.

[2] Oikawa, H., Murayama, G., Sakiyama, T., Takahashi, Y. andIshikawa, T., 2006. Resistance spot weldability of highstrengthsteel (HSS) sheetsforAutomobile. Nippon Steel Technical Report No. 95, 385, 39-45.

[3] Uthaisangsuk, V., Prahl, U. andBleck, W., 2011. Modelling of damageandfailure in multiphasehighstrength DP and TRIP steels. EngineeringFractureMechanics, 78(3), 469-486.

[4] ULSAB-AVC, Body StructureMaterials, Technical Transfer Dispatch no.6, May, 2001

[5] Granbom, Y., 2010. Structureandmechanicalproperties of dualphasesteels, Doctoralthesis, $24-25$

[6] FCA Welding General Standart (2018) 